\title{
Wonderen als tekenen van heiligheid
}

\author{
M. Lindeijer S.J.
}

\begin{abstract}
Miracles, like the saints, are one of the most wondrous parts of the life of the Church since the earliest times. As 'the finger of God' pointing to sanctity (pope Francis), they play a particular role in canonization. The procedures to ascertain miracles, 95\% of them healings, have been refined over the past four centuries, particularly in the 20th century, which also saw fundamental developments in the theology of miracles. Since 1983 fewer miracles have been required for a beatification or canonization. Some candidates for sainthood have been raised to the altar on the basis of a single miracle, based on the common intercession of the saints.
\end{abstract}

\section{De wondere wereld van het canonieke wonder}

In de katholieke kerk gelden heiligverklaringszaken als causae maiores, zaken van groter belang, en zoals alle zaken van groter belang krijgen slechts weinigen ermee te maken. Voor het merendeel van de bisschoppen en het overgrote merendeel van de priesters blijft het canonieke onderzoek naar martelaarschap, heroïsche deugden en wonderen een vreemd en ver land dat ze nooit zullen betreden. Maar wie zich interesseert in heiligheid en in de wonderen die daarmee van oudsher in verband worden gebracht, doet er goed aan om eens op verkenning te gaan in de wondere wereld van het canonieke wonder. De auteur van dit artikel heeft zeven jaar in Rome voor de zaken van de heiligen gewerkt; hij heeft groot respect gekregen voor de grondige manier waarop men daar vermeende wonderen onderzoekt - een grondigheid die past bij hun zeldzame, wonderschone aard én bij de waardigheid van hun almachtige Bewerker.

\section{Het wonder in de recente katholieke leer}

In 1951 verscheen een opmerkelijk artikel in de Osservatore Romano: mgr. Alfredo Ottaviani, assessor van het $\mathrm{H}$. Officie, deed een oproep tot grotere voorzichtigheid wat betreft het geloof in tekenen en wonderen, dit naar aanleiding van een reeks dubieuze Mariaverschijningen in diverse landen sinds de jaren 1930. 'Geen enkele katholiek vraagt zich af of wonderen mogelijk zijn 
of twijfelt dat ze werkelijk gebeuren', zo begint het artikel. Waren het heilswerk en de goddelijke natuur van Jezus niet bewezen door wonderen? Had de jonge kerk niet de bijzondere bijstand van de heilige Geest ervaren in de gaven die de apostelen bezaten? En die hulp zal met de kerk zijn tot einde der tijden, zoals bleek uit de wonderen die nog steeds geschiedden. Als voorbeeld noemt Ottaviani de wonderen in de heiligverklaringszaken, die 'zowel wetenschappelijk als theologisch rigoureus worden geverifieerd', en voegt daaraan toe dat de gestrengheid waarmee de wonderbaarlijke genezingen in Lourdes worden onderzocht algemeen bekend is. ${ }^{1}$

Het artikel van Ottaviani, die naam zou maken als de aanvoerder van de conservatieve factie op het Tweede Vaticaans Concilie, tekent een omslag in de katholieke theologie van het wonder. Wie - zo schreef hij - had vijftig jaar geleden gedacht dat de kerk haar eigen kinderen zou moeten manen tot voorzichtigheid wat betreft zogenaamde wonderen? Kwam de aanval op het geloof in wonderen toen niet vooral van 'wetenschappelijke' positivisten van buiten de kerk? Het Eerste Vaticaans Concilie had over wonderen en profetieën gesproken als 'allerzekerste tekenen van de goddelijke openbaring en toegankelijk voor eenieders verstand', en de negatie van die geloofswaarheid plechtig veroordeeld; in 1910 zou ze worden opgenomen in de zogeheten antimodernisteneed, die van kracht bleef tot 1967. ${ }^{2}$ Het Tweede Vaticaanse Concilie hernam het argument van de wonderen, echter zonder expliciet naar het vorige concilie te verwijzen: Jezus Christus zelf - aldus de concilievaders - vervult en voltooit de openbaring, die slechts op de laatste plaats door wonderen wordt bekrachtigd. ${ }^{3}$ In verband met de heiligen wordt zelfs niet over wonderen gesproken, maar over 'de schitterende beoefening van de christelijke deugden en de bijzondere gunsten van God', en wordt duidelijk gesteld dat onze voornaamste verbinding met de heiligen gelegen is in de gezamenlijke verheerlijking van de drie-ene God, meer dan in het navolgen van hun voorbeeld of het inroepen van hun voorspraak. ${ }^{4}$

1 Engelse vertaling in: A. Ottaviani, 'True Christianity, Signs and Wonders', The Irish Ecclesiastical Record 75 (1951), 334-339.

2 H. Denzinger en A. Schönmetzer (red.), Enchiridion symbolorum, definitionum et declarationum de rebus fidei et morum, Barcinonae-Friburgi Brisgoviae-Rome 19766, *3009, 3034, 3539.

3 Dogmatische constitutie Dei verbum over de openbaring, n. 4. Cf. dogmatische constitutie Lumen gentium over de Kerk, n. 5, en verklaring Dignitatis humanae over de godsdienstvrijheid, n. 11. P. Sbalchiero, L'Église face aux miracles. De l'Évangile à nos jours, Parijs 2007, 315-317.

4 Lumen gentium, n. 50. 
Met een theologie van het wonder die meer uitgaat van het relationele dan van het sensationele, verbaast het niet dat er in de jaren 1970 gepleit werd om in heiligverklaringszaken de zware eis van wonderen terug te brengen tot de eenvoudiger te bewijzen faam van wonderen, dat wil zeggen de algemene reputatie van een machtige voorspreker bij God te zijn. Paus Paulus VI moet er niet principieel tegen zijn geweest, getuige het feit dat de suggestie gedaan werd in La Civiltà Cattolica, het officieuze tijdschrift van het Vaticaan. ${ }^{5}$ Maar evenals in andere postconciliaire bewegingen tot vernieuwing zou er hier weinig veranderen: in toespraken tot de Congregatie voor de Zaken van de Heiligen bevestigen de pausen Johannes Paulus II (1988), Benedictus XVI (2006) en Franciscus (2019) dat wonderen van grote betekenis zijn als een goddelijke verlichting en bevestiging van het oordeel dat het kerkelijk leergezag uitspreekt over een kandidaat-heilige. Paus Franciscus vertelt: 'We hebben eens met kardinaal Amato [prefect van de Congregatie] gesproken over de noodzaak van het wonder. Er moet een wonder zijn, want precies dat is de vinger Gods. Zonder een duidelijke tussenkomst van de Heer kunnen we niet vooruitgaan in de zaken ter heiligverklaring.' ${ }^{\prime}$ Niettemin heeft Franciscus al meermaals mensen heiligverklaard zonder het vereiste wonder, door ervan te dispenseren (bijv. bij de canonisatie van Johannes XXIII in 2014) of door gebruik te maken van de zogeheten equipollente heiligverklaring - een canonisatie 'van gelijke kracht', maar zonder diocesaan proces. Deze variant was eigenlijk bedoeld voor pre-Tridentijnse cultussen, waarbij een lokale heiligenverering door de paus werd goedgekeurd voor de universele kerk. ${ }^{7}$

\section{Korte geschiedenis van het canonieke wonder}

$\mathrm{Al}$ in de tweede eeuw na Christus werd aan de heiligen (aanvankelijk vooral de martelaren) een 'kracht' toegeschreven die het smeekgebed zozeer kon

5 H. Misztal, Le cause di canonizzazione. Storia e procedura (Congregazione delle Cause dei Santi: Sussidi per lo studio delle cause dei santi, 8), Città del Vaticano 2005, 70-72. J.L. Gutiérrez, Studi sulle cause di canonizzazione (Pontificia Università della Santa Croce: Monografie giuridiche, 27), Milaan 2005, 322-323.

6 Toespraken van resp. 19 nov. 1988, 24 april 2006 en 12 dec. 2019, beschikbaar via www. vatican.va.

7 Het (oneigenlijke) gebruik van laatstgenoemde procedure, die sinds 1970 buiten werking was gesteld, zou het onderwerp van een aparte studie kunnen zijn. 'Diario Vaticano/In pochi mesi sei nuovi santi canonizzati fuori dalle regole', Chiesa.espressonline.it (2014): 22 pars. [online tijdschrift], geraadpleegd op 9 maart 2020; beschikbaar via http://chiesa.espresso.repubblica.it/articolo/1350746.html. M. Callebat, 'La nature juridique du miracle dans le modus procedendi des causes de canonisation', in: Ph.-M. Margelidon, Le miracle et la foi. Actes du colloque des 21-22 octobre 2016 à Rocamadour, Parijs 2017, 319-372, 369-371. 
versterken dat bij hun graven wonderen geschiedden. Het toezicht op de orthopraxie van de heiligencultus, die niet altijd gevrijwaard bleef van bijgelovige praktijken, kwam toe aan de bisschoppen. Met de centralisatie van het kerkelijk bestuur in de elfde en twaalfde eeuw werd het eindoordeel bij heiligverklaringen een pauselijk prerogatief, maar de vereisten veranderden niet. Paus Innocentius III vatte ze in 1199 kort en bondig samen als virtus morum et veritas signorum, vrij vertaald: 'deugdzame zeden, bekrachtigd door wonderen'. Die wonderen werden meer en meer het voorwerp van aanvullend onderzoek door de Heilige Stoel, omdat de lokale bisschop, die soms zelf belang had bij de gevraagde canonisatie, niet altijd een gedegen en betrouwbaar dossier indiende. ${ }^{8}$

In het kader van de 16de-eeuwse katholieke reformatie (vroeger 'Contrareformatie' genoemd), onder meer naar aanleiding van de protestantse kritiek op excessen in de heiligencultus, werd de procedure van de heiligverklaring verder uitgewerkt en aangescherpt. Daarbij moet vooral de stichting van de Ritencongregatie in 1588 worden genoemd en de wetgeving van paus Urbanus VIII (1623-1644). Laatstgenoemde stelde het ambt van de 'promotor van het geloof (promotor fidei) in, beter bekend als de advocaat van de duivel, die belast was met de kritische studie van de deugden én de wonderen. ${ }^{9} \mathrm{De}$ strengere regels hadden tot gevolg dat er in de processen steeds minder gesproken werd over de moeilijk te verifiëren wonderen die de dienaar Gods tijdens zijn of haar leven zou hebben verricht, terwijl er steeds meer postume wonderen werden geëist al naar gelang er getuigen gehoord konden worden die de dienaar Gods persoonlijk hadden gekend: twee wonderen, wanneer de zaligverklaring berustte op ooggetuigen; vier wonderen wanneer er alleen getuigen van horen zeggen waren; en in beide gevallen nog eens twee wonderen voor de heiligverklaring. Voor de wonderen zelf gold dat ze alleen bewezen konden worden aan de hand van ooggetuigen en 'bevestigende getuigen' (contestes). In de jaren 1710-1720 werden mede dankzij de zeer bekwame promotor van het geloof Prospero Lambertini (de latere paus Benedictus XIV) de normen nog aangescherpt wat betreft de consultatie van medici bij de studie van vermeende wonderen door de Ritencongregatie. ${ }^{10}$ Genezingen

8 Sbalchiero, L'Église face aux miracles, 39-45, 105-122.

9 J. Duffin, Medical Miracles. Doctors, Saints, and Healing in the Modern World, Oxford 2009, 12-14.

10 F. Antonelli, De inquisitione medico-legali super miraculis in causis beatificationis et canonizationis (Studia Antoniana cura Pontificii Athenaei Antoniani edita, 18), Rome 1962, 10-17. 
waren in de vroege $17^{\mathrm{e}}$ eeuw al een belangrijk onderdeel geweest van de wonderdossiers; in de loop van de tijd gingen ze echter 90 tot $95 \%$ van het totale aantal voorgestelde wonderen vormen, naast opwekkingen uit de dood, wonderbaarlijke reddingen of vermenigvuldigingen van voedsel. ${ }^{11}$

Het kerkelijk wetboek van 1917 hernam de bestaande procedures en normen zonder al te grote wijzigingen: bij het diocesaan onderzoek naar een vermeend wonder moest niet alleen de behandelende arts gehoord worden, maar moest er ook een arts aanwezig zijn om te assisteren bij de getuigenverhoren; de genezen personen moesten onderzocht worden door een deskundige, benoemd door de bisschop; bij het Romeins onderzoek moest in elke fase het oordeel gevraagd worden van één of twee bij de Ritencongregatie geaccrediteerde deskundigen. In het geheel van de procedure woog het oordeel van de medici echter minder zwaar dan dat van de theologen, die als groep gehoord werden - reden voor paus Pius XII om in 1948 als experiment een Medische Commissie in te stellen. Sinds 1959 maakt dit orgaan, nu het Medisch Consult genoemd, vast deel uit van de Congregatie voor de Zaken van de Heiligen (afgesplitst van de Ritencongregatie in 1969). Het sterk toegenomen werk door de snelle groei van het aantal heiligverklaringszaken, zeker sinds het pontificaat van Johannes Paulus II, wordt wat betreft de wonderen enigszins beperkt door het bijstellen van de vereisten. Het in 1983 door dezelfde paus afgekondigde reglement van de Congregatie, dat wat betreft het vereiste aantal wonderen de praktijk sinds het Heilig Jaar 1975 codificeert, vraagt één wonder plus een 'echte faam van wonderen' voor een zaligverklaring, en een tweede wonder van ná de zaligverklaring, voor een heiligverklaring; bij de martelaren wordt nu gewoonlijk afgezien van een wonder voor de zaligverklaring. ${ }^{12}$

\section{De huidige onderzoeksprocedure}

Het diocesane onderzoek naar het martelaarschap, de heroïsche deugden en de wonderen op voorspraak van kandidaat-heiligen wordt sinds 2007 geregeld

11 Duffin, Medical Miracles, 17-21. Pierre Delooz, 'Questions aux théologiens après une enquête sur des miracles', Revue théologique de Louvain 29 (1998), 161-179, 162-166.

12 Misztal, Le cause di canonizzazione, 75-76. Cf. A. Royo, 'I miracoli nelle cause dei santi', in: V. Criscuolo et al. (red.), Le cause dei santi. Sussidio per lo Studium, Città del Vaticano 20184, 105-122, 114-116. F. Veraja, Le cause di canonizzazione dei santi. Commento alla legislazione e guida pratica, Città del Vaticano 1992, 83. 
door de pauselijke instructie Sanctorum Mater. ${ }^{13}$ Bij een vermeende wonderbaarlijke genezing overhandigt de postulator (de vertegenwoordiger van degenen die de heiligverklaring vragen) aan de bevoegde bisschop een overzicht van de feiten, een lijst van getuigen (onder wie de betrokken artsen en verplegers) en het medische dossier van de genezen persoon (art. 38). Daarop benoemt de bisschop een medisch expert, die het dossier bestudeert en helpt met het opstellen van vragen voor het getuigenverhoor; deze expert is ook aanwezig bij het verhoor zelf, om desgewenst verduidelijkende vragen te kunnen stellen (art. 60, 81). De instructie raadt aan dat de medische expert een verslag schrijft ten behoeve van het nadere onderzoek in Rome, waarin hij of zij een oordeel geeft over de kwaliteit van de medische en andere getuigendeskundigen (art. 93). Als de genezen persoon nog leeft, moet deze door twee artsen afzonderlijk worden onderzocht om te zien - met bijzondere aandacht voor de pathologie waarvan de persoon zegt genezen te zijn - of de genezing volledig en blijvend is. De twee artsen moeten ook afzonderlijk hun bevindingen op schrift stellen en als getuigen worden gehoord (art. 109-110). ${ }^{14}$ De vragen die de Congregatie voor de Zaken van de Heiligen suggereert voor het verhoor, geven aan waarop gelet moet worden om van een wonder te kunnen spreken: de genezing moet onmiddellijk, volledig en blijvend zijn en op geen enkele andere manier kunnen worden verklaard; logischerwijs onderzoekt men liefst de genezing van ernstige ziekten met een ongunstige prognose. Wat betreft het theologische aspect moet vooral de aard en wijze van de ingeroepen voorspraak van de kandidaat-heilige worden onderzocht. ${ }^{15}$

De Romeinse fase van het onderzoek wordt geregeld door de apostolische constitutie Divinus perfectionis Magister (1983)16 en meer in het bijzonder door de interne reglementen van de Congregatie voor de Zaken van de

13 Beschikbaar via: http://www.vatican.va/roman_curia/congregations/csaints/documents/ rc_con_csaints_doc_20070517_sanctorum-mater_en.html.

14 Het belang dat gehecht wordt aan het oordeel van de betrokken medici wordt nog onderstreept door de procedures die voorzien zijn voor het geval dat de behandelende arts geen mondelinge of schriftelijke getuigenis wil afleggen voor de kerkelijke rechtbank (art. 107108).

15 'Interrogatori sul miracolo', in: Criscuolo et al. (red.), Le cause dei santi, 675-678. Cf. de praxis gecodificeerd door Prospero Lambertini (Benedictus XIV), in: Misztal, Le cause di canonizzazione, 72 .

16 Beschikbaar via:http://www.vatican.va/content/john-paul-ii/en/apost_constitutions/documents/hf_jp-ii_apc_25011983_divinus-perfectionis-magister.html. 
Heiligen (2000) ${ }^{17}$ en het Medisch Consult (2016). ${ }^{18}$ Eerst maakt de postulator onder leiding van een relator (een begeleider vanuit de Congregatie) een chronologisch overzicht van de ziekte en de genezing, en een samenvatting van de getuigenissen en documenten die verzameld zijn tijdens het onderzoek in het bisdom. Deze stukken worden voorgelegd aan twee ex officio deskundigen, van wie minstens één een positief oordeel moet geven, alvorens de zaak kan worden besproken door de zeven leden van het Medisch Consult (incluis de genoemde twee deskundigen). Wanneer minstens vijf van de zeven consultoren van mening zijn dat de genezing niet wetenschappelijk verklaard kan worden, gaat de Positio super miro (het 'wonderdossier') naar het acht leden tellende Theologisch Congres, voorgezeten door de promotor van het geloof. Deze moet zich met een twee-derde meerderheid voor de zaak uitspreken, wil deze geëvalueerd kunnen worden door de kardinalen en bisschoppen van de Congregatie. Hun oordeel wordt ten slotte door de prefect van de Congregatie overgebracht aan de paus, 'aan wie alleen - aldus Divinus perfectionis Magister - het recht toekomt om te bepalen of aan dienaren Gods een publieke kerkelijke cultus moet worden gegeven' (III, n. 15). ${ }^{19}$

In alle fasen van het onderzoek wordt expliciet voorzien in de mogelijkheid van andere soorten wonderen, waarvoor dan deskundigen moeten worden ingeschakeld, maar zoals gezegd betreft het overgrote merendeel van de zaken onverklaarbare genezingen, niet alleen omdat die het meest doen denken aan de doven, blinden en lammen die Jezus tijdens zijn leven genas, maar ook en vooral omdat die het meest gedegen kunnen worden onderzocht. De Congregatie beschikt over een groot aantal geaccrediteerde medisch experts, en kan en zal nog andere experts zoeken, al naargelang de aard van de zaak. Het is hun taak om zo precies mogelijk de diagnose, de ernst en de prognose van de ziekte vast te stellen, om de therapie te bezien die de genezen persoon genoten heeft en hoe die zich verhoudt tot de genezing, en om te beoordelen of de genezing inderdaad onmiddellijk, volledig en blijvend is geweest.

17 Merkwaardig genoeg is dit reglement niet beschikbaar via de website van het Vaticaan en is het niet opgenomen in het handboek van de Congregatie voor de Zaken van de Heiligen. Men vindt het echter in: L. Porsi, Leggi della Chiesa su beatificazione e canonizzazione dall'anno 993 all'anno 2000. Collezione, Rome 2006, 472-493.

18 Beschikbaar via: http://press.vatican.va/content/salastampa/it/bollettino/pubblico/2016/09/ 23/0666/01504.html.

19 R.J. Sarno, 'Fase Romana della Causa', in: Criscuolo et al. (red.), Le cause dei santi, 452-514, 487-497. 
Vooral dit laatste, het quoad modum van de genezing, noopt tot grote voorzichtigheid: prof. Patrizio Polisca, jarenlang voorzitter van het Medisch Consult, waarschuwt bijvoorbeeld voor kankers en andere kwaadaardige gezwellen die plotseling kunnen verdwijnen, op natuurlijke wijze, en waarvan men pas na tien jaar zeker weet dat ze definitief verdwenen zijn. ${ }^{20}$ Eén van Polisca's voorgangers, dr. Raffaello Ernestini, heeft verklaard dat hij precies in wonderen is gaan geloven door zijn ervaringen in het Medisch Consult: de degelijke dossiers, de zorgvuldige studie, de moeite die wordt gedaan om tot een volledig beeld van de zaak te komen, bijvoorbeeld wanneer het gaat om een vermeend wonder van lang geleden of uit een streek waar de medische wetenschap nog in de kinderschoenen staat. Op de vraag of hij zich ooit onder druk gezet gevoeld heeft wanneer paus Johannes Paulus II bijzondere interesse toonde in een zaak, bijvoorbeeld vanwege een gewenste zaligverklaring tijdens één van diens reizen, antwoordde Ernestini: 'Zeker, maar we moeten objectief blijven. Wij hebben de macht om een zaak te stoppen'. ${ }^{21}$ Elke postulator zal beamen dat wanneer er bij een vermeende wonderbaarlijke genezing ook maar de geringste twijfel bestaat, men de zaak beter kan laten vallen, omdat ze toch niet verder zal komen dan de medische experts in Rome.

\section{Wonderen vroeger en nu}

In de afgelopen vijftig jaar is de historiografische aandacht voor 'kerkelijke wonderen' vooral uitgegaan naar de Middeleeuwen. ${ }^{22}$ Men constateert daarbij een accentverschuiving in de jaren 1960: voorheen hield men zich vooral bezig met het bewijzen of ontkrachten van historische wonderen, nu richt men de aandacht op de ervaring van het wonder - op het verhaal dus, meer dan op de feiten, waarbij slechts een enkeling opmerkt dat als er niets gebeurd zou zijn, er ook geen verhaal was geweest. ${ }^{23}$ De invalshoek van het wonder als spiegel van de historische mentaliteit is zeker vruchtbaar gebleken, ook in de schaarsere studies betreffende de moderne tijd, in het bijzonder de zeventien-

20 P. Polisca, 'Note di logica e metodologia medica', in: Criscuolo et al. (red.), Le cause dei santi, 437-444.

21 K.L. Woodward, Making Saints. Inside the Vatican: Who Become Saints, Who Do Not, and Why..., Londen 1991, 198-201.

22 Een goede recente publicatie in dit verband is: Chr. Krötzl en S. Katajala-Peltomaa (red.), Miracles in Medieval Canonization Processes (International Medieval Research, 23), Turnhout 2018.

23 B. Maës, 'Les historiens devant les récits modernes de miracles de la fin du XIXe siècle à nos jours', Revue d'histoire de l'Église de France 86 (2000), 459-467. 
de en achttiende eeuw. Men ziet bijvoorbeeld hoe het begrip van het wonder veranderde met de beleving van het lichaam en van ziekten, maar ook hoe het onderzoek naar wonderen bepaald kon worden door de agenda van degenen die de heiligverklaringszaak promootten (zo gaven de jezuïeten in Napels rond 1720 duidelijk de voorkeur aan wonderen die de eigen orde goed deden uitkomen). ${ }^{24}$ De canonieke wonderdossiers van de nieuwste tijd echter worden nauwelijks bestudeerd, hoewel ze in principe toegankelijk zijn voor historici (althans na de zalig- of heiligverklaring). ${ }^{25}$ Bovendien zijn de weinige onderzoekers die ze wel bestuderen vaak geen geschiedkundigen, zoals de socioloog Pierre Delooz (1921-2014) en de theoloog René Laurentin (19172017), om twee bekende namen te noemen; beiden pleitten eind jaren 1990 voor een meer integrale, minder reductionistisch-wetenschappelijke benadering van het wonder, met aandacht vooral voor Gods werken in het complexe wezen dat de mens is - ziel, lichaam, geest - en voor de psychosomatiek. ${ }^{26}$

Hoewel de nieuwe bredere kijk op het wonder ontegenzeggelijk zijn voordelen heeft, blijven de resultaten van het canoniek onderzoek naar vermeende wonderen op voorspraak van kandidaat-heiligen tot de verbeelding spreken. Of liever: ze appelleren aan onze zin voor geloof en godsdienst. Delooz telde in 1998 zo'n 1200 wonderen die waren goedgekeurd sinds 1588, waarvan ruim $90 \%$ genezingen, hetzij van ziekten, hetzij van de gevolgen van een ongeluk. De conclusies van zijn sociologische onderzoek zijn weinig verrassend: wonderen gebeuren daar waar om een heiligverklaring wordt gebeden; in het geval van een stichter(es) van een religieuze orde of congregatie zijn het meestal de eigen leden op wier gebed het wonder wordt verkregen; men geneest het vaakst van ziekten die niet dodelijk maar sterk invaliderend zijn (paralyse) of die zeer bedreigend lijken (kanker), met op de derde plaats de diverse vormen van tuberculose, die vooral genezen werden in de negentien-

24 A. Burkardt, Les clients des saints. Maladie et quête du miracle à travers les procès de canonisation de la première moitié du XVIIe siècle en France (Collection de l'École francaise de Rome, 338), Rome 2004. G. Sodano, 'Miracolo e canonizzazione. Processi napoletani tra XVI e XVIII secolo', in: S. Boesch Gajano en M. Modica (red.), Miracoli. Dai segni alla storia (Sacro/santo, nuova serie, 1), Rome 2000, 171-195.

25 De verslagen van het Medisch Consult van de wonderen die in 1983-1995 hebben geleid tot een zalig- of heiligverklaring zijn samengebracht door Andreas Resch in zijn Miracoli dei beati (twee vols.) en Miracoli dei santi (Congregazione delle Cause dei Santi: Sussidi per lo studio delle cause dei santi, 3-5), Città del Vaticano 1999-2002. De auteur heeft de drie delen tevens in eigen beheer in het Duits uitgebracht.

26 P. Delooz, 'Questions aux théologiens après une enquête sur des miracles', Revue théologique de Louvain 29 (1998), 161-179. 
de eeuw, toen de ziekte werd geïdentificeerd maar nog niet kon worden behandeld. ${ }^{27}$ 'Nood leert bidden' zei het spreekwoord al, en 'van je vrienden moet je het hebben', ook in de hemel.

De in de negentiende eeuw opgekomen apologetische geschiedschrijving, die het bestaan van God en de waarheid van de katholieke leer wilde bewijzen met de methoden van de rationalistische tegenstanders, is niet verdwenen in de jaren 1960.28 De theoloog Wilhelm Schamoni (1905-1991) publiceerde nog in 1971 een overzicht van wonderen genomen uit de dossiers ter zalig- of heiligverklaring, met de veelzeggende titel Parallelen zum Neuen Testament, die vijf jaar later een derde druk beleefde met een nieuwe, niet minder programmatische titel, namelijk Wunder sind Tatsachen. En inderdaad, "blinden zien en lammen lopen, melaatsen genezen en doven horen, doden staan op' (Mt. 11: 5), op het gebed van de heiligen, tijdens hun leven of na hun dood. Voor alleen al de jezuïet en martelaar Johannes de Britto (1647-1693), zaligverklaard in 1853 en heiligverklaard in 1947, noemt Schamoni achtereenvolgens de genezing van een melaatse (1723), van een doofstom en lam meisje (1721), en van een man met een verdorde arm (1719). Het enige dat lijkt te veranderen bij wonderen die in de nieuwste tijd geschiedden, is dat de diagnose preciezer wordt, zoals de genezing van blindheid veroorzaakt door netvliesloslating van beide ogen op voorspraak van de heilige Petrus Maria Chanel (1803-1841) in 1890, de genezing van acute spinale kinderverlamming op voorspraak van de heilige Maria Mazzarello (1837-1881) in 1916, de genezing van chronische middenoorontsteking met botvraat op voorspraak van de heilige Michaëla van het Allerheiligst Sacrament (1809-1865) in 1930, of de genezing van levercirrose met buik- en huidwaterzucht bij een zware drinker op voorspraak van de zalige Clelia Barbieri (1847-1870) in 1954. ${ }^{29}$ In elk van de vier gevallen was de modaliteit zodanig - inclusief het plotse herstel van de onherstelbaar beschadigde organen - dat er toen én nog steeds gesproken mag worden van een wetenschappelijk onverklaarbare genezing. 'De lezer die zich verontrust voelt door zoveel vernietigende kritiek op de nieuwtestamentische wonderen, waaraan tegenwoordig vreemd genoeg de theologen knagen en niet de geschiedkundigen', aldus Schamoni, die 'zal de

27 Delooz, 'Questions', 162-166.

28 Maës, 'Les historiens devant les récits modernes de miracles', 460-461.

29 W. Schamoni, Parallelen zum Neuen Testament aus Heiligsprechungsakten übersetzt, Abensberg 1971, 115-122, 126-127, 162-163 (de Britto); 7-22 (Chanel), 98-103 (Mazzarello), 135-142 (Michaela), 163-170 (Barbieri). In de derde druk vermeldt Schamoni ook een opwekking uit de dood, genomen uit zijn eerdere boek Auferweckungen vom Tode aus Heiligsprechungsakten übersetzt, Helmeringhausen 1968. 
verbazingwekkende gelijkenis opmerken tussen de zo korte verhalen van de Evangeliën en de zo uitvoerig gedocumenteerde casussen in de heiligverklaringsdossiers.' 30

Een medicus die zich aan de kant van de genoemde geschiedkundigen geschaard heeft, is de Canadese hematoloog Jacalyn Duffin. In de jaren 1980 was ze als expert geraadpleegd inzake een wonderbaarlijke genezing van ernstige acute leukemie, een ervaring die haar ertoe bracht om de 1200 wonderen te analyseren die canoniek onderzocht en goedgekeurd waren tussen 1588 en 1999. Zij concludeert dat 'de structuur van de genezingsverhalen en de neiging tot onderzoek, met zijn vertrouwen op de wetenschap, opmerkelijk constant zijn in de vele verschillende tijden en plaatsen' . Die statische structuur weerspiegelt volgens haar de algemene menselijke strijd om te leven, betekenisvol te leven, in het aanschijn van de dood. ${ }^{31}$

Wonderen mogen feiten zijn, maar meer dan de apologie zouden ze de inspiratie mogen dienen - opbouwen dus in plaats van verdedigen. Een boekje als dat van de filosoof Dario Composta (1917-2002) uit 1981, met veertien wonderen uit de periode 1920-1970, wil precies dat doen: de lezer informeren, zonder in te gaan op de hele wetenschappelijke problematiek, en opwekken tot vertrouwen in de voorspraak van de heiligen. In het voorwoord schrijft de voormalige kardinaal-prefect van de Congregatie voor de Zaken van de Heiligen, Corrado Bafile, geheel in lijn met de theologie van het Tweede Vaticaans Concilie, dat zijn intensieve betrokkenheid bij de studie van de wonderdossiers hem 'een gevoel van geestelijke bemoediging' had gegeven. Zij tonen 'dat God ook vandaag op wonderbaarlijke wijze zijn nabijheid doet gevoelen en grote werkzaamheid verleent aan de voorspraak van zijn dienaren'. Het had hem tevens doen beseffen 'dat de Heer ons de gave van deze wonderen niet alleen geeft om de gebeden te verhoren van mensen die om hulp smeken en om zijn dienaren te verheerlijken, maar ook om bemoediging te schenken aan de christengelovigen die kennisnemen van deze stralende uitingen van de gemeenschap van de heiligen'.32

\section{Op voorspraak van ...}

In de wetenschappelijke literatuur en in de handboeken van heiligverklaringszaken wordt weinig gesproken over het onderzoek van vermeende wonderen door het Theologisch Congres, hoewel het twee leden meer telt dan het

30 Schamoni, Parallelen zum Neuen Testament, xI.

31 Duffin, Medical Miracles, 184, 190.

32 D. Composta, Il miracolo: realtà o suggestione? Rassegna documentata di fatti straordinari nel cinquantennio 1920-1970, Rome 1981, 8. 
Medisch Consult en het laatste deskundige oordeel velt, voordat het kerkelijk leergezag in strikte zin zich uitspreekt. Het oordeel van de theologen geldt twee aspecten: het wonderbaarlijk karakter van de genezing (of een ander buitengewone gebeurtenis) die volgens de medische wetenschap onverklaarbaar is, en het verband tussen de genezing en het smeekgebed op voorspraak van de kandidaat-heilige. Zeker bij een unaniem positief oordeel van het Medisch Consult (wat meestal het geval is) is het niet moeilijk om tot morele zekerheid te komen wat betreft het wonderbare van de genezing, terwijl 'het uit de omstandigheden, zoals beschreven door de getuigen, niet moeilijk is om de band aan te tonen tussen het aanroepen van de dienaar Gods en de wonderbaarlijke gebeurtenis'. ${ }^{33}$ De criteria betreffende de voorspraak, die Lambertini in de achttiende eeuw codificeerde, zijn nog altijd van kracht: ze moet uitdrukkelijk zijn; ze moet voorafgaan aan het vermeende wonder; en ze moet alleen tot de kandidaat-heilige zijn gericht. In geval er meerdere hemelbewoners zijn aangeroepen, moet vastgesteld worden tot wie er het meest gebeden is, wiens voorspraak chronologisch het dichtst bij het vermeende wonder ligt, en wie vanuit kerkelijk perspectief het dichtst bij de troon Gods staat: wanneer bijvoorbeeld gelijktijdig een heilige en een kandidaat-heilige zijn aangeroepen, wordt de voorspraak aan de eerste toegeschreven; de enige wier aanwezigheid nooit een belemmering is om de voorspraak aan een kandidaat-heilige toe te schrijven is de Moeder Gods, wier medewerking in Gods heilswerk voorondersteld wordt. ${ }^{34}$

Sinds de codificatie van Lambertini zijn er twee theologische vragen gerezen aangaande de voorspraak bij een wonder. De eerste vraag is of een wonder kan worden toegeschreven aan meerdere belijders (niet-martelaren) tegelijk? Nadat Leo XIII bevestigend had geantwoord in de zaak van de Zeven Stichters van de Servieten konden naar analogie, op basis dus van een sterke geestelijke eenheid, wonderen worden toegeschreven aan de gezamenlijke voorspraak van de twee zienertjes van Fatima, zaligverklaard in 2000, en aan de echtparen Beltrame Quattrocchi-Corsini en Martin-Guérin (de ouders van Thérèse van Lisieux), zaligverklaard in respectievelijk 2001 en 2008; laatstgenoemd echtpaar is ook heiligverklaard op basis van één wonder, in 2013. ${ }^{35}$ Maar waar nie-

33 Van de 124 vermeende wonderen voorgelegd aan het Medisch Consult tussen maart 1983 en maart 1992 werden er 111 met unanimiteit van stemmen onverklaarbaar geoordeeld. Veraja, Le cause di canonizzazione dei santi, 86-88. Cf. Misztal, Le cause di canonizzazione, 381.

34 Royo, 'I miracoli nelle cause dei santi', 118-119.

35 Gutiérrez, Studi sulle cause de canonizzazione, 325-327. De kwestie van een gezamenlijke zaak voor gehuwde kandidaat-heiligen, die voor het eerst gesteld werd naar aanleiding van echtpaar Martin-Guérin, wordt besproken in: Woodward, Making Saints, 346-352. 
mand in dergelijke gevallen aan het theologisch fundament van een gezamenlijke voorspraak zal twijfelen, lag en ligt dat anders wanneer het om groepen martelaren gaat. Volgens Lambertini kan een wonder slechts aan verschillende martelaren samen worden toegeschreven, wanneer ze tegelijkertijd en in dezelfde omstandigheden hun leven hebben gegeven: de 813 martelaren van Otranto bijvoorbeeld, zaligverklaard in 1771 en heiligverklaard in 2013, waren in enkele dagen tijds door dezelfde vervolgers vermoord omwille van het geloof. Lambertini was bekend met geloofsvervolgingen over een langere periode en op meerdere plaatsen, zoals in het Groot-Brittannië van de Tutors en de Stuarts, maar juist in de zaak van de martelaren van Engeland en Wales werd voor het eerst van zijn criterium afgeweken. In 1970 bepaalde Paulus VI namelijk dat in hun geval - vele tientallen martelaren uit de periode 1535-1679 - nog van gezamenlijke voorspraak kon worden gesproken bij veertig personen. Het feit dat bij de heiligverklaring van de Engelse martelaren John Fisher en Thomas More in 1935 was gedispenseerd van de verplichting van een vastgesteld wonder, was daarbij een zwaarwegend argument. ${ }^{36}$

Men moet hebben ingezien dat het aantal van veertig toch wat arbitrair was, want tijdens het pontificaat van Johannes Paulus II werd dispensatie de regel voor grote groepen martelaren uit één en hetzelfde land; een gedeeld heroïsch verleden lijkt een voldoende theologische grond te zijn voor canonieke heiligheid. ${ }^{37}$ Feit is echter dat sindsdien de zaken van de heiligen meer dan ooit een instrument van pauselijk pastoraal beleid zijn geworden, waarbij het moment van een heiligverklaring, althans wat betreft groepen van martelaren, niet meer bepaald wordt door een wonder van de voorzienigheid, maar door de (reis)agenda van de paus. Op 23 maart 2017 dispenseerde paus Franciscus van een wonder in twee Latijns-Amerikaanse zaken, namelijk van drie Mexicaanse kind-martelaren uit 1529 en van de Braziliaanse martelaren André de Soveral en diens 29 gezellen, gedood in 1645 - twee zaken die probleemloos afgehandeld hadden kunnen worden volgens het oude criterium, als men op een wonder had willen wachten. ${ }^{38}$ Het bericht niet ongeloofwaardig - dat de paus uit persoonlijke affiniteit bereid zou zijn geweest om Soveral en de zijnen heilig te verklaren, doet de vraag stellen of

36 Gutiérrez, a.w., 327-331. P. Molinari, 'Canonization of Forty English and Welsh Martyrs', L'Osservatore Romano, 29-10-1970.

37 Resch, Miracoli dei santi, 202-203.

38 D. Castellano Lubov, 'Ahead of May Papal Trip, Francis Recognizes Miracle Fatima Children', Zenit, 23-3-2017: 6 pars. [online krant], geraadpleegd 17 maart 2020. Beschikbaar via https://zenit.org/articles/ahead-of-may-papal-trip-francis-recognizes-miracle-of-fatimachildren/. 
men met het vereiste wonder niet ook een zekere objectiviteit heeft prijsgegeven. Deze zou in de gemeenschap van de heiligen het zwaartepunt bij de bewoners van het hemelse Jeruzalem hebben gehouden, bij de voorsprekers dus, meer dan bij het volk Gods onderweg. ${ }^{39}$ Wonderen hielden dat volk vroeger al op de goede weg.

M. Lindeijer S.J. werkt in bisdom Breda als vicaris-generaal, met bijzondere aandacht voor de missionaire kerk.

39 Cf. https://en.wikipedia.org/wiki/Martyrs_of_Natal, geraadpleegd op 17 maart 2020. Eenzelfde motivatie lag ten grondslag aan o.a. de heiligverklaring van de jezuïet Pierre Favre in 2014. 